\title{
Perimbangan Keuntungan dalam Rantai Pasok Agroindustri Kelapa Sawit
}

\author{
Syarif Hidayat ${ }^{1}$ \\ ${ }^{1}$ Program Studi Teknik Industri, Fakultas Sains dan Teknologi, Universitas Al Azhar Indonesia, Jalan \\ Sisingamangaraja, Kompleks Masjid Agung Al Azhar, Kebayoran Baru, Jakarta Selatan 12110 \\ Penulis untuk Korespondensi/E-mail: syarif hidayat@uai.ac.id
}

Abstrak - Masalah umum yang dihadapi dalam pengembangan agroindustri di Indonesia adalah bahwa potensinya belum sepenuhnya mampu diwujudkan secara berdaya-guna dan berhasilguna karena keterbatasan sumberdaya permodalan, hambatan teknologi dan rendahnya efektivitas kelembagaan yang terkait. Juga terdapat ketimpangan antara sisi hulu dan hilir pada rantai nilainya. Untuk komoditas kelapa sawit keuntungan terbesar terdapat pada sisi hilir pada para pengusaha dan eksporter dan distributor produk turunannya seperti minyak goreng, olein, dll. jauh melebihi tingkat keuntungan para petani di sisi hulu. Sangat perlu dilakukan upaya penyetaraan tingkat keuntungan sepanjang jalur rantai pasok untuk menjamin kelangsungan hidupnya, karena seluruh aktor rantai pasok saling membutuhkan, dan runtuhnya salah-satu mata rantai karena rugi atau bangkrut akan meruntuhkan keseluruhan rantai pasok. Pada makalah ini penulis menyusun model matematis dari keuntungan pada jaringan rantai pasok kelapa sawit dengan pendekatan kesetaraan rasio benefit terhadap cost $(=\mathrm{B} / \mathrm{C})$ yang diuraikan oleh Tarigan pada disertasinya (2008). Kelayakan usaha mensyaratkan bahwa Rasio $\mathrm{B} / \mathrm{C}$ harus $>1$, dan pada seluruh aktor rantai pasok nilai ini diupayakan setara dengan mengubah-ubah nilai harga beli bahan/produk atau biayabiayanya.

Kata Kunci - Agroindustri, Kelapa Sawit, Rantai Pasok Distribusi, Rasio B/C.

Abstract - The general problem in the development of agroindustry is that its potencial has not been fully utilized effectively and efficiently due to the constraints in the financial and technology resources, and institutional weaknesses. Another major problem is the financial imbalance between the supply, distributor, retailer and consumer sides. In the palm oil industry the highest profit margin enjoyed in the downstream of the chain, the producers, exporters, and distributors of products derivatives like frying oil, olein, etc, far exceeding the profit received by the farmers in the upstream. It is imperative to balance the profitability levels along the supply chain to ensure the survival and continuity of the chain, otherwise the whole chain will collapse if any of the dependent actors suffer losses or go bankrupt. In this paper the writer endeavour to develop the mathematical model of the profit in the palm oil supply chain network using the balancing of $\mathrm{B} / \mathrm{C}$ ratio approach described by Tarigan in his dissertation (2008). Feasibility analysis of a project dictates that $\mathrm{B} / \mathrm{C}$ ratio should be $>1$. To obtain a fair balance of profitability overall value of $B / C$ ratio should be the same along the way. This may be achieved by adjusting the selling/buying prices of the raw materials or the costs and expenditures.

Keywords - Agroindustry, Palm Oil, Distribution Supply-Chain, B/C Ratio. 


\section{PENDAHULUAN}

\section{Latar Belakang}

Dengembangan kelapa sawit di Indonesia P sudah dimulai sebelum perang dunia ke dua, dalam bentuk usaha perkebunan besar. Sampai dengan tahun 1978 pengembangan perkebunan besar kelapa sawit sangat terbatas, baik dari segi perkembangan luasannya, produksi maupun perkembangan dunia usahanya. Pola pengembangan baru dengan melibatkan masyarakat dimulai semenjak tahun 1979, yaitu melalui proyek Perkebunan Inti Rakyat (PIR-Bun) yang kemudian dilanjutkan dengan PIR-Trans semenjak tahun 1986. Pada tahun 1968 luas areal baru mencapai 120 ribu Ha, pada tahun 1978 menjadi 250 ribu Ha dan pada tahun 2000 mencapai 3,4 juta $\mathrm{Ha}$, sedangkan tahun 2017 diperkirakan mencapai 12,3 juta $\mathrm{Ha}$ atau peningkatan lebih dari 100 kali lipat. (Ditjenbun, 2015).

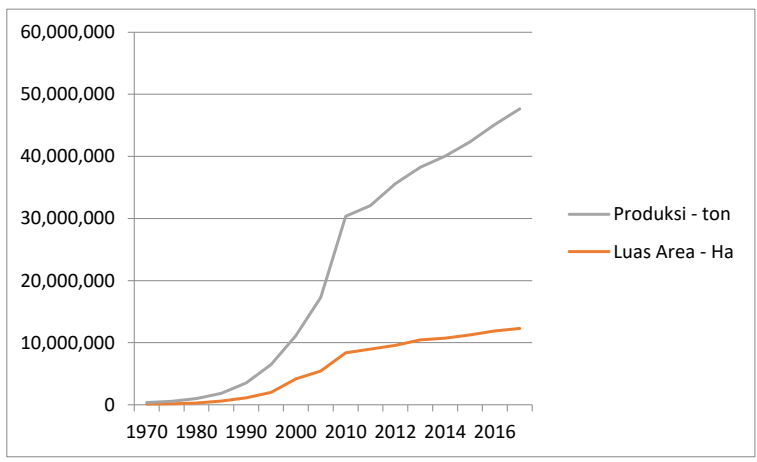

(Sumber: Ditjenbun, 2015)

Gambar 1. Grafik Luas kebun sawit dan produksi CPO 1970-2017

Sejalan dengan perkembangan area, produksi kelapa sawit juga mengalami peningkatan. Pada tahun 1968 produksi CPO baru mencapai 181 ribu ton, kemudian pada tahun 1978 menjadi 501 ribu ton dan pada tahun 1988 naik menjadi 1.713 ribu ton, pada tahun 1997 menjadi 5.385 ribu ton, kemudian pada tahun 2000 menjadi 6.270 ribu ton. Ditinjau dari bentuk pengusahaannya, perkebunan rakyat memberi andil produksi CPO sebesar $24 \%$, perkebunan negara $33 \%$ dan perkebunan besar swasta sebesar $43 \%$. Produksi tersebut akan terus meningkat dimasa datang yang dicerminkan oleh masih luasnya tanaman menghasilkan yang produksinya belum optimal serta tanaman belum menghasilkan (TBM). (Ditjenbun, 2015)
Agroindustri diharapkan dapat menjadi tulang punggung dan motor perekonomian dan pembangunan Indonesia. Hal ini dikarenakan agroindustri mempunyai keunggulan komparatif dan kompetitif yang diantaranya adalah: (1) Agroindustri memiliki keterkaitan yang kuat baik dengan sektor pertanian maupun dengan sektor industri. Dengan demikian agroindustri diharapkan dapat memiliki struktur keterkaitan yang kuat baik ke hulu maupun ke hilir. (2) Agroindustri menggunakan sumber daya yang ada dan dapat diperbaharui, dengan demikian agroindustri diharapkan memiliki keunggulan komparatif dan kompetitif di pasar lokal, nasional dan global. (3) Agroindustri bersifat lentur, dalam arti dapat menampung tenaga kerja dari sektor pertanian maupun industri. Hal ini berarti agroindustri diharapkan dapat menyerap banyak tenaga kerja yang tergeser dari sektor lainnya. (4) Produk agroindustri cukup elastis, sehingga semakin besar tingkat pendapatan masyarakat akan semakin luas pasar bagi produk industri. Konsumen dengan tingkat pendapatan lebih tinggi mau membayar lebih mahal. (Priyarsono, et al. 2006, dan Grice, et al. 2003).

Agroindustri khususnya untuk makanan pokok merupakan kebutuhan sehari-hari bagi masyarakat dimanapun sehingga industri ini akan selalu bertahan walaupun terjadi kesulitan bahan baku maupun sumber daya pendukung produksi ataupun distribusinya. (Brown, et al, 2001). Secara umum dapat dikatakan bahwa perdagangan produk agroindustri memiliki pertanyaan pokok yaitu "bagaimana fair-trade dapat diupayakan agar tingkat keuntungan dapat seimbang" sepanjang rantai pasoknya. (Imhof dan Lee. 2007)

Agroindustri kelapa sawit masih memberikan peluang yang baik untuk mendukung perekonomian Indonesia. Harga produk utamanya (CPO dan PKO) pada Tabel 1 terlihat sedang berfluktuasi sekitar USD 623 dan USD 909 per metric ton pada tahun 2015. Demikian juga produk sampingan dari sisa pohon yang tidak diolah menjadi CPO. Hampir tidak ada bagian pohon kelapa sawit yang tidak dapat dimanfaatkan untuk kebutuhan manusia. (Iyung Pahan, 2007)

\section{Permasalahannya}

Permasalahan pertama adalah bahwa sampai saat ini terjadi ketimpangan antara sisi hulu dan 
hilir pada rantai nilai agroindustri kelapa sawit ini. Keuntungan terbesar pada rantai pasok kelapa sawit (tampak pada Tabel 1) terdapat pada sisi hilir yaitu pada para pengusaha dan eksporter CPO dan produk lanjutannya seperti minyak goreng, olein, dll. Para petani/pekebun di sisi hulu menerima tingkat keuntungan yang lebih rendah dibandingkan dengan keuntungan di sisi hilir.

Tabel 1. Harga CPO dan PKO tahun 2015.

\begin{tabular}{|l|c|c|c|c|c|c|c}
\hline \multicolumn{7}{c}{ Harga produk Minyak Sawit (USD/metric ton) tahun 2015 } \\
\hline & JAN & FEB & MAR & APR & MAY & JUN \\
\hline CPO (Crude Palm Oil) & 688 & 689 & 672 & 662 & 659 & 671 \\
\hline PKO (Palm Kernel Oil) & 1.023 & 1.079 & 1.037 & 985 & 966 & 919 \\
\hline & & & & & & \\
\hline & JUL & AUG & SEP & OCT & NOV & DEC \\
\hline CPO (Crude Palm Oil) & 635 & 549 & 538 & 583 & 558 & 568 \\
\hline PKO (Palm Kernel Oil) & 869 & 739 & 798 & 860 & 785 & 847 \\
\hline \multicolumn{7}{c}{ (Sumber. }
\end{tabular}

(Sumber: Ditjenbun, 2015)

Permasalahan pokok kedua adalah sangat lemahnya kemampuan pengusaha Indonesia dalam "mencari dan menguasai pasar" sawit dan turunannya sehingga hanya mampu mendapatkan pertambahan nilai sangat terbatas sejauh harga CPO ataupun minyak goreng saja. Pertambahan nilai yang jauh lebih tinggi didapat dari penjualan hasil proses selanjutnya dari CPO menjadi produk-produk margarine, olein, stearin, fatty acids, gliserol, dll. Pasar tersebut dikuasai oleh pebisnis mancanegara, yang bahkan menguasai kebun sawit yang ada di Indonesia.

Makalah ini akan mencoba merumuskan suatu formula yang memperlihatkan pertambahan nilai kelapa sawit dari mulai sisi paling hulu (petani) dan paling hilir (distributor/retailer). Konsumen pada sisi ujung dari rantai pasok ini akan membayar harga yang ditetapkan oleh retailer yang kemudian akan menjadi dasar dari tingkat keuntungan yang didapat retailer tersebut setelah dibandingkan dengan harga yang dibayarnya untuk produk akhir. Demikian seterusnya secara berantai maka pada sisi paling hulu petani akan mendapatkan bagian keuntungannya berupa selisih dari harga jual TBS dengan seluruh biaya yang dikeluarkannya sejak penyiapan lahan, pembelian dan penanaman bibit, dan akhirnya pemanenan dan penjualan TBS ke Koperasi dan pabrik CPO.

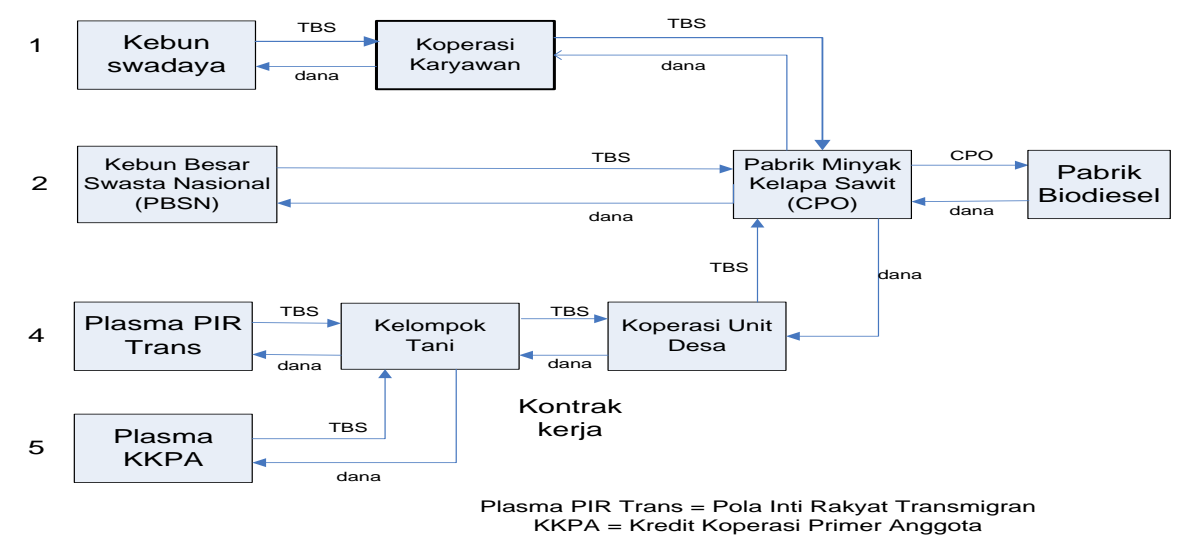

Gambar 2. Jaringan Rantai Pasok Kelapa Sawit - dari petani sampai pabrik Biodiesel.

Gambar 2 menunjukkan diagram jaringan rantai pasok kelapa sawit. Kebun menghasilkan tandan buah sawit (TBS) untuk diperas menghasilkan minyak sawit kasar $(\mathrm{CPO}=$ Crude Palm Oil). Diagram ini digambarkan berdasarkan wawancara dengan beberapa orang pelaku usaha dalam bidang kelapa sawit. Karena kesulitan waktu untuk dapat memperoleh keterangan maka beberapa informasi untuk menggambarkan diagram ini masih belum dapat dikonfirmasikan. Angkaangka terperinci juga masih belum didapat, sehingga diagram hanya menunjukkan gambaran umum jaringan proses rantai pasok kelapa sawit.

Gambar 2 tersebut memperlihatkan adanya 5 macam usaha pada sisi hulu dalam agroindustri kelapa sawit yaitu:

1. Kebun swadaya (rakyat), yang memiliki kebun dengan dana sendiri atau dari warisan, yang tidak mendapatkan bantuan pemerintah maupun perkebunan besar swasta ataupun BUMN. Usaha inilah yang paling menderita pada saat harga TBS/CPO 
turun tajam, karena tidak ada kontrak pembelian dengan pabrik pengolahan kelapa sawit.

2. Kebun Besar Swasta Nasional (KBSN), yang memiliki (baik hak penggunaan ataupun hak milik) kebun sawit ribuan hektar dengan modal sangat besar. KBSN umumnya memiliki pabrik besar pengolahan kelapa sawit menjadi CPO. KBSN umumnya memerlukan kebun swadaya ataupun kebun plasma untuk sumber bahan baku (TBS) bagi pabrik kelapa sawitnya. Dalam hal ini maka kebun yang dimiliki oleh KBSN disebut kebun inti.

3. Kebun Besar PTP Nasional (PTP) yang memiliki kebun ribuan hektar dan umumnya juga memiliki pabrik pengolahan kelapa sawit menjadi CPO. Seharusnya PTP yang memiliki kebun dan pabrik kelapa sawit mengelola kebun plasma milik rakyat, tetapi tidak semuanya melaksanakan hal ini karena satu dan lain alasan.

4. Kebun Plasma PIR atau PIR-TRANS, yang dikelola oleh rakyat didalam kontrak kerja dengan KBSN ataupun PTP. Kontrak ini menjamin bantuan teknis dan prasarana produksi oleh KBSN/PTP; pembelian TBS oleh KBSN atau PTP dengan harga yang baik, tidak terpengaruh oleh fluktuasi harga pasar. Bagi petani hal ini dapat merupakan kerugian bila harga naik tinggi tetapi tetap terpaksa harus menjual sesuai kontrak.

5. Kebun Plasma KKPA (Kredit Koperasi Primer Anggota), yaitu kebun plasma yang dikelola oleh Koperasi. (Hasil wawancara dengan CSR BSP)

\section{Tujuan dan Manfaat}

Tujuan penulisan makalah ini adalah akan mencoba meneliti pola pertambahan nilai yang terjadi sepanjang rantai pasok agroindustri kelapa sawit. Secara khusus ingin diteliti bagaimana industri ini berupaya menjaga kelancaran pasokan bahan baku (TBS) dari lingkungannya dan tetap menjaga kualitas hasil CPO dan memenuhi permintaan pasar terhadap CPO dan produk turunannya.

Manfaat yang ingin dicapai dalam penulisan makalah ini adalah:

1. Mendapatkan gambaran umum dan permasalahan yang dihadapi para stakeholder dalam rantai pasok kelapa sawit dari mulai sisi hulu (petani) sampai hilir.

2. Model yang dihasilkan akan dapat dimanfaatkan sebagai kerangka pikir untuk melakukan upaya-upaya meningkatkan kesejahteraan petani sawit, dalam pengertian bahwa risiko yang ditanggungnya berkurang sedangkan keuntungan baginya meningkat secara optimum.

3. Mendapatkan pola kerjasama yang menjamin keberlangsungan rantai pasok kelapa sawit dari hulu sampai hilir dengan terjadinya kesepakatan atau kontrak yang saling menguntungkan.

\section{TINJAUAN PUSTAKA}

\section{Agroindustri \\ Menurut Djamhari (2004) agroindustri merupakan rangkaian kegiatan agrobisnis berbasis pertanian yang saling berkaitan dalam suatu sistem produksi, pengolahan, distribusi, pemasaran dan berbagai kegiatan atau jasa penunjangnya.}

Keterkaitan struktural antar sub-sistem amat vital dan merupakan kunci sukses dalam membangun agroindustri yang tangguh. Kegiatan agroindustri dapat menghasilkan produk-pangan dan/atau produk nonpangan, dan hampir semua jenis pangan yang dipasarkan dan dikonsumsi berasal dari kegiatan produsen agroindustri di dalam maupun di luar negeri. Untuk mengusahakan terjadinya keseimbangan manfaat untuk semua pelaku dalam jaringan agroindustri akan diperlukan koordinasi kebijakan dengan lembaga terkait, agar kapasitas dan sumberdaya yang terkait dengan agroindustri dapat disinergikan secara efektif. Koordinasi antar pelaku dan pembina usaha akan melibatkan banyak Departemen dan Lembaga pemerintah baik di pusat maupun di daerah.

Lazzarini (2000) menggambarkan jaringan agroindustri secara vertikal (Gambar 3) sehingga merupakan aliran produk disetiap tingkatan rantai pasok dalam konteks jaringan rantai pasok pertanian menyeluruh. Setiap perusahaan diposisikan dalam sebuah titik dalam lapisan jaringan rantai pasok ini. Agroindustri menjadi pusat rantai pertanian yang berperan penting dalam meningkatkan nilai tambah produk pertanian di pasar. Selain 
itu agroindustri membutuhkan pasokan bahan baku yang berkualitas dan jumlah yang sesuai dengan kebutuhan.

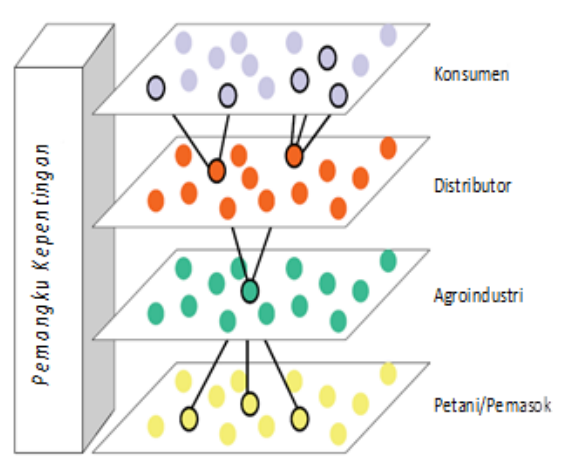

(Sumber : Lazzarini, 2000)

Gambar 3. Jaringan rantai pasok vertikal

\section{Risiko Dalam Pasokan Agroindustri}

Menurut Kersten (2006) saat ini banyak sekali risiko yang dihadapi para pengusaha yang terikat dalam suatu rantai pasok sehingga harus selalu mengamati perkembangan lingkungan dari mulai pemasok bahan, prosesnya sendiri, pengendalian kualitas dll, serta mengamati trend (lihat gambar 4). Kemudian Wu (2006) menulis bahwa pasokan bahan baku sangat berisiko dalam hal pemilihan pemasok sehingga perusahaan harus dapat menjaga hubungan baik dan kerjasama dengan para pemasok.

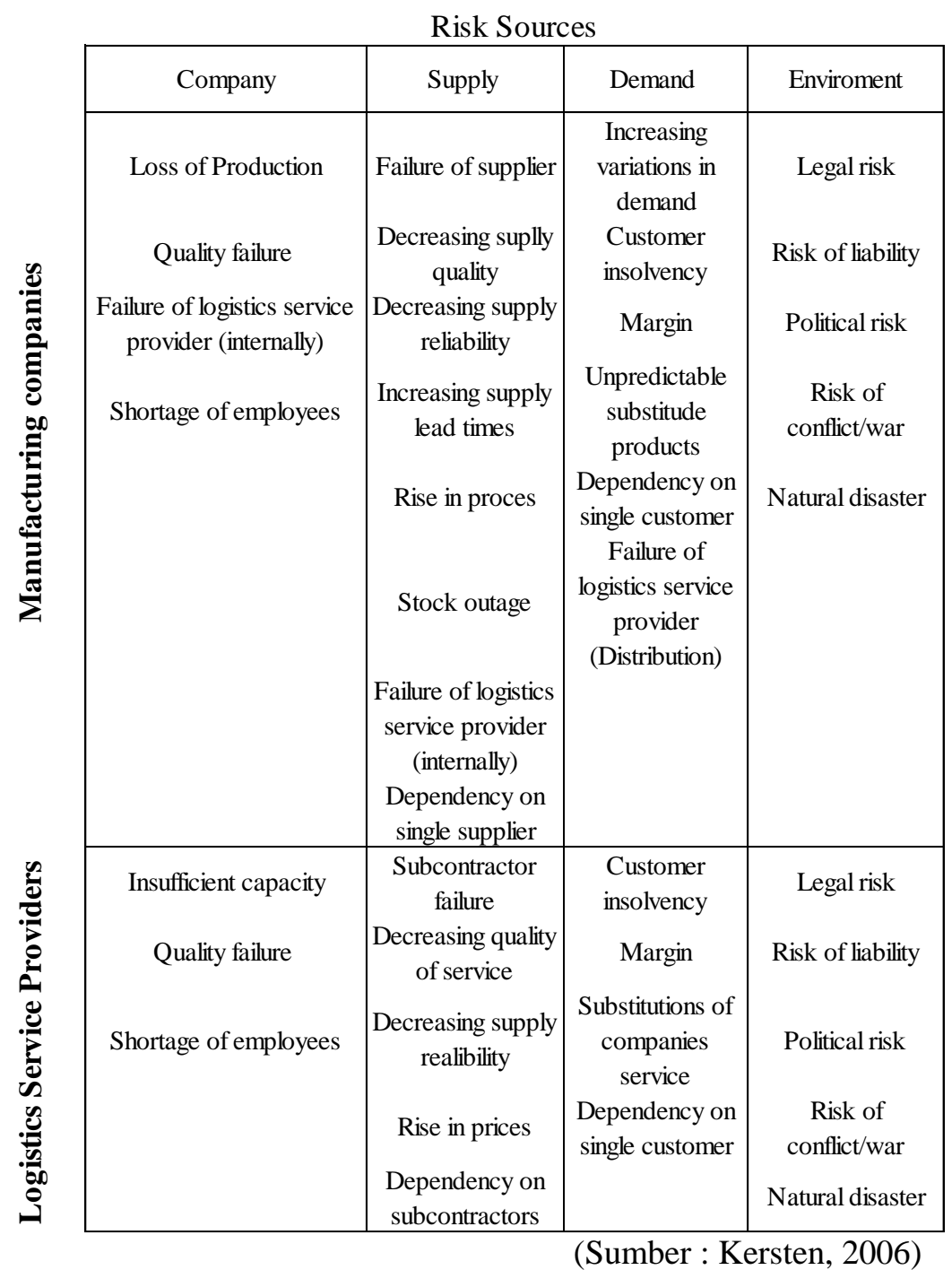

Gambar 4. Klasifikasi risiko dalam agroindustri menurut Kersten, et al.

Untuk mengatasi atau mitigasi risiko-risiko tersebut masing-masing aktor berupaya "mengamankan" usahanya. Salah satu upaya yang didukung pemerintah adalah program Inti- 
Plasma yang diuraikan pada paragraph Permasalahannya diatas yang menjamin pembelian TBS oleh perusahaan pengolah dengan harga yang ditetapkan oleh Dinas Perkebunan Provinsi Jambi setiap 2 minggu.

Risiko terbesar bagi petani swadaya adalah bila tidak ada pembeli panen TBS-nya karena alasan apapun. Untuk petani swadaya memang tidak ada kontrak sehingga mereka harus mencari sendiri pasar pembelinya. Salah satu keengganan pembeli produk petani swadaya adalah bahwa kualitas (randemen) buah masih rendah karena banyak faktor, terutama bibit dan manajemen budidaya yang tidak baik.

\section{METODOLOGI: PENDEKATAN RASIO BENEFIT/COST}

Analisa kelayakan suatu investasi atau usaha umumnya menggunakan 4 besaran yaitu Nilai Net Present Value (NPV); Internal Rate of Return (IRR); Payback Period (PBP) dan Banefit/Cost Ratio (B/C Ratio atau BCR). Besaran yang berkaitan dengan keuntungan adalah BCR sedangkan 3 yang lain lebih mengutamakan arus uang keluar dan masuk.

Rantai pasok agroindustri terdiri dari pelakupelaku dangan asumsi-asumsi interaksi seperti dibawah ini:

- Setiap pelaku pada jaringan menghendaki memaksimumkan keuntungannya;

- Kuantitas dan harga jual produk merupakan hasil kesepakatan antara penjual dan pembeli berdasarkan hukum ekonomi.

- Terdapat biaya fixed dan biaya variable bagi semua aktor pada rantai pasok.

- Setiap pelaku, anggota jaringan rantai pasok mendapatkan informasi yang lengkap tentang demand dan biaya-biaya.

- Benefit diartikan sebagai (margin) keuntungan yang bisa didapat suatu aktor, dengan mengurangi penjualan dengan biaya-biaya

- Rasio Benefit/Cost dihitung sebagai margin keuntungan dibagi dengan total biayabiaya.

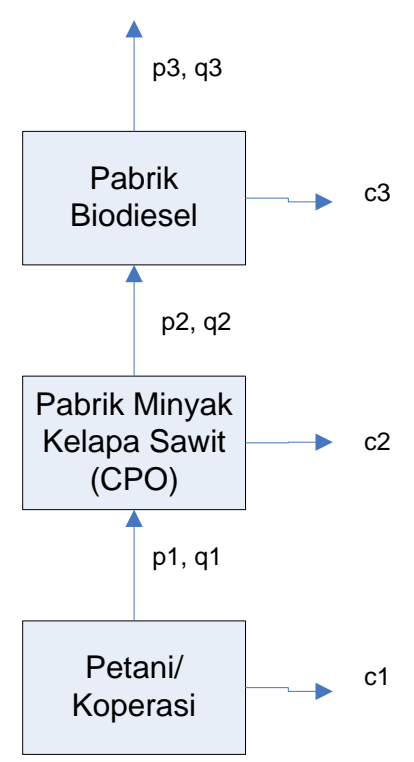

Gambar 5. Jaringan rantai pasok kelapa sawit yang dibahas pada makalah ini

Didefinisikan besaran-besaran sebagai berikut:

$\mathrm{i}=1$ adalah petani/koperasi

$\mathrm{i}=2$ adalah pabrik CPO

$\mathrm{i}=3$ adalah pabrik biodiesel

$\mathrm{p}_{\mathbf{i}}=$ harga jual produk aktor $\boldsymbol{i}$

$\mathrm{q}_{\mathrm{i}}=$ kuantitas penjualan produk aktor $\boldsymbol{i}$

$\mathrm{s}_{\mathbf{i}}=$ tingkat penjualan produk aktor $\boldsymbol{i}$

$\mathrm{b}_{\mathbf{i}}=$ benefit /profit aktor $\boldsymbol{i}$

$\mathrm{cv}_{\mathbf{i}}=$ biaya variabel aktor $\boldsymbol{i}$

$\mathrm{cf}_{\mathbf{i}}=$ biaya tetap (fixed) aktor $\boldsymbol{i}$

$\mathrm{c}_{\mathrm{i}}=$ total biaya aktor $\boldsymbol{i}$

$\mathrm{BCi}=$ rasio benefit/cost aktor $\boldsymbol{i}$

Penjualan atau sales actor $i$ adalah

$S_{i}=p_{i} * q_{i}$

$c_{i}=$ total biaya $i=\left(c v_{i} * q_{i}+c f_{i}\right)$

Benefit untuk aktor i didefinisikan sebagai berikut:

$$
\begin{aligned}
b_{i} & =p_{i} * q_{i}-c_{i} \\
& =p_{i} * q_{i}-\left(c v_{i} * q_{i}+c f_{i}\right) \\
& =q_{i} *\left(p_{i} * c v_{i}\right)-c f_{i}
\end{aligned}
$$

$\mathrm{B} / \mathrm{C}$ ratio adalah benefit dibagi dengan total cost:

$$
B C i=\left\{p_{i} * q_{i}-(c v i * q i+c f i)\right\} / c_{i}
$$


$B C i=\left\{q_{i} *\left(p_{i}-c v_{i}\right)-c f_{i}\right\} / c_{i}$

Kesemua nilai tersebut akan dihitung menggunakan nilai sukubunga $18 \%$ per tahun dan untuk setiap tahun akan diproyeksikan ke saat ini (present value). Dengan demikian akan didapat nilai-nilai present value dari benefit $=$ profit $=b_{i}$, dan biaya $=\operatorname{cost}=c_{i}$.

Kemudian akan didapatkan nilai $\mathrm{BCR}$ degan formula :

$B C R=\frac{P V(\text { benefits })}{P V(\text { costs })}$

Untuk kemudahan perhitungan diambil masa hidup 10 tahun saja, walaupun normalnya siklus hidup pohon sawit adalah 25 tahunan.

Untuk mendapatkan kesetaraan tingkat keuntungan bagi semua aktor maka nilai $\mathrm{BCi}$ harus sama untuk semuanya (petani/Koperasi, Pabrik CPO, maupun pabrik biodiesel).

Apabila pada suatu perhitungan terdapat nilai berbeda maka perlu dirubah besarnya harga atau biaya untuk suatu aktor sehingga didapat nilai $\mathrm{BC}_{\mathrm{i}}$ yang sama.

\section{Penerapan Perhitungan Keuntungan}

Untuk setiap aktor akan dihitung berapa besarnya penjualan untuk tingkat produksi $\mathrm{q}$ yang sama; harga jual, dan biaya-biaya; kemudian dihitung nilai $\mathrm{BC}_{\mathrm{i}}$.

Khususnya untuk koperasi, perhitungannya agak lain karena organisasi koperasi adalah milik anggota, sehingga keuntungan sebagai organisasi dikembalikan kepada anggota sebagai Sisa Hasil Usaha.

Dalam hal rantai pasok ini Koperasi Unit Desa (KUD) hanya menerima fee dari anggota dan dari perusahaan pembuat CPO sehingga dianggap menjadi kesatuan dengan petani. Hal ini terlihat pada gambar 5 .

Asumsi-asumsi yang diambil pada perhitungan ini adalah sbb (Tabel 2).
Tabel 2. Asumsi Dasar Perhitungan BCR

\begin{tabular}{lcc}
\hline \multicolumn{1}{c}{ Umum } & & \multicolumn{1}{c}{ catatan } \\
\hline Hari kerja pabrik setahun & $300 \mathrm{hari}$ & \\
Hari kerja pabrik sebulan & $25 \mathrm{hari}$ & \\
Jam kerja pabrik sehari & $16 \mathrm{jam}$ & \\
Randemen TBS rata - rata & $22 \%$ & Data primer diambil \\
Harga pembelian TBS & $700 \mathrm{rp} / \mathrm{kg}$ & dari PT AGW/AMM \\
Harga pembelian CPO & $6000 \mathrm{rp} / \mathrm{kg}$ & bagian dari BSP Jambi \\
& $6000000 \mathrm{rp} / \mathrm{ton}$ & \\
& $600 \$ / \mathrm{ton}$ & \\
Harga jual biodiesel & $10224 \mathrm{rp} / \mathrm{kg}$ & \\
& $1022 \$ / \mathrm{ton}$ & \\
Tingkat suku bunga & 0.18 & \\
niai tukar US\$ & $10000 \mathrm{rp} / \$$ & \\
& & \\
Petani/Koperasi & & \\
Seorang petani 2 hektar & $6000 \mathrm{~kg}$ TBS/bln \\
Biaya tetap - per petani & $1000000 \mathrm{rp}$ & $750000-2000000$ \\
Biaya variabel - per petani & $120 \mathrm{rp} / \mathrm{kg}$ tbs antara 111-130 \\
Untuk 60 ton/tbs per jam & $60000 \mathrm{~kg}$ & $750000-2000000$ \\
Biaya tetap petani & $20000000 \mathrm{rp}$ & $300 \mathrm{rp} / \mathrm{kg}$ tbs antara 111-130 \\
Biaya variabel petani & &
\end{tabular}

Tabel 3. Lanjutan

\begin{tabular}{|c|c|c|}
\hline Pabrik CPO & & \\
\hline Randemen TBS & 0.22 & unit antara $0.17-0.26$ \\
\hline Kapasitas proses & 60 & ton tbs/jam \\
\hline Produksi CPO /jam & 13.2 & ton tbs/jam \\
\hline Produksi CPO /bulan & 5280 & ton tbs/jam Data primer diambil \\
\hline Biaya tetap & 400000000 & rp/sebulan dari PT AGW/AMM \\
\hline Perlu CPO untuk biodesel & 100000 & ton TBS bagian dari BSP \\
\hline Rasio TBS/CPO & 4.65 & Jambi \\
\hline Kuantitas TBS & 465000 & ton/tahun \\
\hline Biaya variabel & 200000000 & $\mathrm{rp} / \mathrm{sebulan}$ \\
\hline Total biaya & 12400000000 & $\mathrm{rp} /$ sebulan \\
\hline $\mathrm{H}$ harga $\mathrm{CPO} /$ ton & 6000000 & $\mathrm{rph} / \mathrm{ton}$ \\
\hline Sales CPO & 31680000000 & Rph sebulan \\
\hline \multicolumn{3}{|l|}{ Pabrik Biodiesel } \\
\hline Kapasitas proses & $\begin{array}{r}114000 \\
380\end{array}$ & $\begin{array}{l}\text { ton/tahun Menggunakan data } \\
\text { ton/hari tugas kuliah TIN771 }\end{array}$ \\
\hline Kebutuhan CPO & $\begin{array}{r}100000 \\
333.33\end{array}$ & $\begin{array}{r}\text { ton/th } \\
\text { ton/hari }\end{array}$ \\
\hline Biaya tetap & $\begin{array}{r}229281216844 \\
764270723\end{array}$ & $\begin{array}{l}\text { rphpertahun } \\
\text { rphperhari }\end{array}$ \\
\hline \multirow[t]{2}{*}{ Biaya variabel } & 227812300000.00 & rphpertahun \\
\hline & 759374333 & rph per hari \\
\hline \multirow[t]{3}{*}{ Harga jual biodiesel } & 700 & $\$ /$ ton \\
\hline & 795 & $\mathrm{rph} / \mathrm{kg}$ \\
\hline & 80 & $\$ /$ ton \\
\hline
\end{tabular}

Tabel 4. Asumsi Dasar Perhitungan BCR Variasi-1

\begin{tabular}{|c|c|c|}
\hline$\underline{\text { Umum }}$ & & Catatan \\
\hline Hari kerja pabrik setahun & 300 hari & \\
\hline Hari kerja pabrik sebulan & 25 hari & \\
\hline Jam kerja pabrik sehari & 16 jam & \\
\hline Randemen TBS rata-rata & $22 \%$ & Data primer diambil \\
\hline Harga pembelian TBS & $1,900 \mathrm{rp} / \mathrm{kg}$ & dari PT AGW/AMM \\
\hline \multirow[t]{3}{*}{ Harga pembelian $\mathrm{CPO}$} & $7,230 \mathrm{rp} / \mathrm{kg}$ & bagian dari BSP Jam \\
\hline & $7,230,000 \mathrm{rp} / \mathrm{ton}$ & \\
\hline & $723 \$ /$ ton & \\
\hline \multirow[t]{2}{*}{ Harga jual biodiesel } & $10,224 \mathrm{rp} / \mathrm{kg}$ & \\
\hline & $1,022 \$ /$ ton & \\
\hline Tingkat suku bunga & 0 & \\
\hline nilai tukar US\$ & $10,000 \mathrm{rp} / \$$ & \\
\hline PETANI/KOPERASI & & \\
\hline seorang petani 2 hektar & $6,000 \mathrm{~kg} \mathrm{TBS} / \mathrm{bln}$ & \\
\hline Biaya tetap - per petani & $1,000,000 \mathrm{rp}$ & $750,000-2,000,000$ \\
\hline Biaya variabel - per petani & $120 \mathrm{rp} / \mathrm{kg}$ tbs & antara $111-130$ \\
\hline Untuk 60 ton/tbs per jam & $60,000 \mathrm{~kg}$ & \\
\hline Biaya tetap petani & $20,000,000 \mathrm{rp}$ & $750,000-2,000,000$ \\
\hline Biaya variabel petani & $300 \mathrm{rp} / \mathrm{kg}$ tbs & antara $111-130$ \\
\hline
\end{tabular}


Data rinci untuk rencana pabrik biodiesel diberikan pada Lampiran. Untuk mendapatkan nilai-nilai BCR yang mendekati harapan maka beberapa besaran biaya maupun produksi telah disesuaikan. Depresiasi dan bunga pinjaman diabaikan. Data untuk pabrik biodiesel adalah data hipotetis. Data primer untuk petani dan pabrik CPO diambil dari PT AGW (Agrowiyana) dan AMM (Agro Mitra Madani) yang merupakan bagian dari PT Bakrie Sumatera Plantations Tbk (BSP) yang beroperasi di propinsi Jambi.

\section{HASIL DAN PEMBAHASAN}

Sebagaimana diuraikan diatas pada paragraph Metodologi pendekatan penyetaraan rasio $\mathrm{B} / \mathrm{C}$ mengharuskan perhitungan benefit atau keuntungan dan biaya-biaya masing-masing aktor pada rantai pasok. Keuntungan dan biayabiaya ini harus didasarkan kepada tingkat produksi yang setara, dalam hal ini setara dengan kapasitas produksi pabrik CPO yaitu 60 Ton/jam TBS. Demikian juga dengan pabrik biodiesel harus menggunakan tingkat kapasitas yang sama, sehingga bila kapasitas berbeda maka diambil angka yang proporsional, artinya angka kapasitas kebutuhan CPO bagi pabrik biodiesel diambil sama dengan tingkat produksi pabrik CPO pada 100,000 ton. Kebutuhan biaya dan profit dianggap linier proporsional.

Dengan komposisi asumsi data seperti tampak pada Tabel 2 didapat hasil BCR yang berbeda antara Petani/Koperasi $(=1.05)$, Pabrik CPO $(=2.38)$ dan pabrik biodiesel $(=2.86)$ (lihat Tabel 5). Secara harfiah hal ini dapat diartikan seperti ini:

Petani harus mengeluarkan biaya 1 rupiah untuk setiap keuntungan 1.05 rupiah yang diinginkannya; sedangkan pabrik CPO menerima rp 2.38 dan Biodiesel menerima rp 2.86 untuk pengeluaran rp 1.

Dengan merubah-rubah nilai asumsi maka kita akan mendapatkan nilai BCR yang berubah sesuai formulasi perhitungan pada masingmasing aktor. Tabel 4 memperlihatkan komposisi nilai jual/beli TBS petani rp 1,900 per kg dan harga CPO rp 7,230 yang akan memberikan nilai BCR sama bagi ketiga aktor yaitu 2.86. (Tabel 5). Nilai BCR yang sama ini dapat kita artikan bahwa tingkat keuntungan untuk ketiga aktor adalah sama besar.

Untuk variasi nilai harga jual produk masingmasing yaitu TBS, CPO dan Biodiesel yang berubah maka akan didapat nilai BCR yang berubah pula. Bagi pabrik biodiesel perubahan pada nilai tukar rupiah, nilai sukubunga pinjaman, pajak, harga bahan baku lain dll akan merubah nilai BCR.

Perubahan nilai tukar rupiah tidak mempengaruhi nilai BCR untuk petani/koperasi dan pabrik CPO. Perubahan nilai sukubunga mempengaruhi nilai BCR untuk ketiga aktor.

\section{KESIMPULAN DAN SARAN}

\section{Kesimpulan}

Dari hasil perhitungan diatas dapat dilihat bahwa untuk mencapai perimbangan peningkatan nilai tambah yang diterjemahkan sebagai kesetaraan rasio $\mathrm{B} / \mathrm{C}$ perlu dilakukan perubahan-perubahan pada harga jual/beli bahan ataupun penurunan biaya-biaya produksi ataupun operasional.

Formulasi model perhitungan pendapatan dan biaya akan merupakan faktor pokok pada kemampuan model tersebut dalam mengikuti pergerakan kebutuhan pemakai model dalam membuat keputusan sehari-hari dalam dunia usaha.

Berapa bagus atau berapa adil perimbangan keuntungan dalam rantai pasok suatu agroindustri akan sangat tergantung kepada banyak hal, akan tetapi yang terpenting adalah bahwa secara keseluruhan pada rantai pasok terdapat kesadaran bersama bahwa saling ketergantungan memerlukan kemauan untuk berbagi keuntungan oleh karena bila ada salah satu aktor yang terpaksa bangkrut maka dampak buruknya akan menimpa aktor yang lain.

\section{Saran}

Untuk melengkapi analisa yang komprehensif pada keseluruhan rantai pasok agroindustri kelapa sawit dari hulu sampai hilir perlu dilakukan pengumpulan data yang lebih akurat dan mewakili cukup banyak aktor yang terkait. Demikian juga rincian biaya dapat lebih teliti 
untuk setiap aktor sehingga dapat dilakukan penyesuaian atau pemilihan unsur biaya yang lebih layak dalam mencapai kesetaraan rasio $\mathrm{B} / \mathrm{C}$.

Selanjutnya dapat dilakukan analisa sensitivitas yaitu mencoba-coba merubah besaran-besaran nilai asumsi sehingga terjadi batas maksimal atau minimal yang tetap dapat memberikan hasil kesetaraan yang diharapkan.
Selain itu dapat dilakukan penelitian dengan pendekatan berbeda menggunakan konsep game theory yang diuraikan oleh Kogan dan Tapiero (2007), atau pendekatan matematis seperti yang diuraikan oleh Ingene dan Parry (2005).

Tabel 5. Kesetaraan Rasio Benefit/Cost

\begin{tabular}{|c|c|c|c|}
\hline Indikator Pembanding & Petani/Koperasi & Pabrik CPO & Pabrik Biodiesel \\
\hline & $\mathrm{kg}$ & & \\
\hline Kapasitas proses/produksi & 6,000 tbs/petani/bulan & $\begin{array}{l}60 \text { ton tbs/jam } \\
\text { ton tbs/jam }\end{array}$ & 380 ton/hari \\
\hline harga satuan bahan baku & lihat bya $\mathrm{ttp} / \mathrm{var}$ & $700 \mathrm{rp} \mathrm{TBS} / \mathrm{kg}$ & $6,000,000$ rupiah \\
\hline kuantitas b baku/hari & lihat bya $\mathrm{ttp} / \mathrm{var}$ & $60,000 \mathrm{~kg} / \mathrm{jam}$ & 333 ton/hari \\
\hline harga produk & $700 \mathrm{rp} \mathrm{TBS} / \mathrm{kg}$ & $6,000,000 \mathrm{rph} /$ ton & $700 \$ /$ ton \\
\hline kuantitas produk & 6,000 kg TBS/bln & 5,280 ton & 380 ton \\
\hline biya tetap & $1,000,000$ /petani/bulan & $400,000,000$ & $764,270,723 \mathrm{rp}$ \\
\hline biaya variabel - rupiah & 300 /petani/bulan & $200,000,000 \mathrm{rp} /$ tahun & $759,374,333 \mathrm{rp} / \mathrm{tahun}$ \\
\hline Rasio BCR & 1.05 & 2.38 & 2.86 \\
\hline
\end{tabular}

Tabel 6. Kesetaraan Rasio Benefit/Cost

\begin{tabular}{|c|c|c|c|}
\hline Indikator Pembanding & Petani/Koperasi & Pabrik CPO & Pabrik Biosiesel \\
\hline Kapasitas proses/produksi & $6,000 \mathrm{~kg}$ tbs/petani/bulan & $\begin{array}{ll}60 & \text { ton tbs/jam } \\
\text { ton tbs/bulan }\end{array}$ & 380 ton/hari \\
\hline harga satuan bahan baku & lih bya ttp/var & $1,900 \mathrm{rp} \mathrm{TBS} / \mathrm{kg}$ & $7,230,000$ rupiah \\
\hline kuantitas b baku/hari & lih bya ttp/var & $60,000 \mathrm{~kg} / \mathrm{jam}$ & 333 ton/hari \\
\hline harga produk & $1,900 \mathrm{rp} \mathrm{TBS} / \mathrm{kg}$ & $7,230,000 \mathrm{rph} /$ ton & $700 \$ /$ ton \\
\hline kuantitas produk & $6,000 \mathrm{~kg} \mathrm{TBS} / \mathrm{bln}$ & 5,280 ton & 380 ton \\
\hline biaya tetap & $1,000,000 \quad /$ petani/bulan & $400,000,000$ & $764,270,723 \mathrm{rp}$ \\
\hline biaya variabel - rupiah & 300 /petani/bulan & $200,000,000 \mathrm{rp} /$ tahun & $759,374,333 \mathrm{rp} /$ tahun \\
\hline Rasio BCR & 2.86 & 2.86 & 2.86 \\
\hline
\end{tabular}

\section{KESIMPULAN DAN SARAN}

\section{Kesimpulan}

Dari hasil perhitungan diatas dapat dilihat bahwa untuk mencapai perimbangan peningkatan nilai tambah yang diterjemahkan sebagai kesetaraan rasio $\mathrm{B} / \mathrm{C}$ perlu dilakukan perubahan-perubahan pada harga jual/beli bahan ataupun penurunan biaya-biaya produksi ataupun operasional.

Formulasi model perhitungan pendapatan dan biaya akan merupakan faktor pokok pada kemampuan model tersebut dalam mengikuti pergerakan kebutuhan pemakai model dalam membuat keputusan sehari-hari dalam dunia usaha. 
Berapa bagus atau berapa adil perimbangan keuntungan dalam rantai pasok suatu agroindustri akan sangat tergantung kepada banyak hal, akan tetapi yang terpenting adalah bahwa secara keseluruhan pada rantai pasok terdapat kesadaran bersama bahwa saling ketergantungan memerlukan kemauan untuk berbagi keuntungan oleh karena bila ada salah satu aktor yang terpaksa bangkrut maka dampak buruknya akan menimpa aktor yang lain.

\section{DAFTAR PUSTAKA}

[1] D.Bangun, Identifying Risks CPO Plantation and Milling, BEI NEWS Edition 15 Year IV, June-July 2003.

[2] I.Pahan, Panduan Lengkap Kelapa Sawit. Penebar Swadaya, Depok, 2007

[3] Direktotat Jendral Perkebunan (Ditjenbun), 2015. Statistik Perkebunan Kelapa Sawit 2015-2017.

[4] S.Imhof and A.Lee, Assessing the Potential of Fair Trade for Poverty Reduction and Conflict Prevention: A Case Study of Bolivian Coffee Producers. Europa-Institut, University of Basel, 2007

[5] J. Vorst, Performance Measurement In Agri-Food Supply-Chain Networks. An Overview. Wageningen University, The Netherlands, 2004

[6] C. Djamhari, Orientasi Pengembangan Agroindustri Skala Kecil Dan Menengah; Rangkuman Pemikiran. Infokop Nomor 25 Tahun XX, 2004

[7] S.F. Andi, Pedoman Pembangunan Agribisnis Kelapa Sawit 1.500 Ha Pola Terpadu, Direktorat Jenderal Bina Produksi Perkebunan Departemen Pertanian, 2004

[8] C.A. Ingene, and M.E. Parry, Mathematical Models of Distribution Channels, Kluwer Academic Publishers, New York, Boston, Dordrecht, London, Moscow, 2005
[9] Ikatan Akuntan Indonesia. 1998. Pernyataan Standar Akuntansi Keuangan No. 27 (Revisi 1998). Akuntansi Perkoperasian. Ikatan Akuntan Indonesia.

[10] K. Kogan, and C.S.Tapiero, Supply Chain Games: Operations Management and Risk Valuation. Springer Science, Polytechnic University of New York, 2007

[11] W. Kersten, P. Hohrath and M.Boeger, An Empirical Approach To Supply Chain Risk Management: Development of a Strategic Framework, Hamburg University of Technology, 2006

[12] S.G.Lazzarini, Integrating Supply Chain And Network Analyses: The Study Of Netchains. 2000

[13] D.S. Priyarsono et al, Peranan Investasi Di Sektor Pertanian Dan Agroindustri Dalam Penyerapan Tenaga Kerja Dan Distribusi Pendapatan: Pendekatan Sistem Neraca Sosial Ekonomi, Fakultas Ekonomi dan Manajemen, Institut Pertanian Bogor, 2006

[14] D.Tarigan, Strategi Pengembangan Agroindustri Sutera Alam Melalui Pendekatan Klaster, Disertasi, Fakultas Teknologi Pertanian, Institut Pertanian Bogor, 2008

[15] J. Grice, S. Paton, and D.Blines, Organic Sugar: End-User Support and Grower Perception. RIRD Publication. 2003

[16] O. Brown, C. Charveriat, and D. Eagleton, The Coffee Market - a Background Study, Oxfam: International Commodity Research, 2001

[17] T. Wu, J. Blackhurst, and V.Chidambaran. A model for inbound supply risk analysis. Elsevier. 2006

[18] S. Hidayat, Analisis Teknoekonomi Pendirian Pabrik Biodiesel Dari Minyak Kelapa Sawit, Tugas Makalah, IPB, 2007

[19] ADOT, Traffic Studies Benefit/Cost Ratio Economic Analysis, Traffic Engineering Policies, Guidelines, and Procedures, 2004 